\author{
Ademir Antonio Cazella ${ }^{1}$ \\ Clóvis Dorigon ${ }^{2}$ \\ Cristiano Nunes $\mathrm{Nesi}^{3}$ \\ Ludivine Eloy ${ }^{4}$
}

\title{
Sistemas agrícolas e alimentares de famílias rurais: análise da multilocalização familiar na região Oeste de Santa Catarina
}

DOI:10.36920/esa-v28n1-2

\section{Apresentação}

O tema das migrações de agricultores familiares para as cidades foi sempre analisado em termos de êxodo rural, dando pouca atenção para a importância e o significado da circulação de pessoas e recursos entre os membros de famílias que residem em diferentes locais, mas que participam da mesma unidade produtiva. A questão da multilocalização das famílias em zonas urbanas e rurais e suas relações com a transformação dos sistemas produtivos e formas de manejo dos recursos naturais foram bastante tratadas por geógrafos e antropólogos em territórios indígenas e quilombolas (NASUTI et al., 2015; ELOY; BRONDIZIO; DO PATEO, 2015), enquanto no âmbito dos estudos da agricultura familiar, essa discussão se orientou para a compreensão dos fenômenos da

\footnotetext{
${ }_{1}^{1}$ Doutorado em Ordenamento Territorial pelo Centre d'Etudes Supérieures d'Aménagement Tours/França. Professor titular no Programa de Pós-Graduação em Agroecossistemas da Universidade Federal de Santa Catarina (PGA/UFSC). E-mail: ademir.cazella@ufsc.br.

2 Doutorado em Engenharia de Produção pela Universidade Federal do Rio de Janeiro (UFRJ) e doutorado sanduíche pela École des Hautes Études en Sciences Sociales (EHESS) de Paris. Pesquisador da Empresa de Pesquisa Agropecuária e Extensão rural de Santa Catarina/Centro de Pesquisa para a Agricultura Familiar (Epagri/Cepaf). E-mail: cdorigon@epagri.sc.gov.br.

${ }^{3}$ Doutorado em Agronomia (Produção Vegetal) pela Universidade Federal do Paraná (UFPR). Professor adjunto e membro do corpo docente do Programa de Pós-Graduação em Sanidade e Produção Animal da Universidade do Oeste de Santa Catarina (Unoesc). Pesquisador da Empresa de Pesquisa Agropecuária e Extensão Rural de Santa Catarina/Centro de Pesquisa para a Agricultura Familiar (Epagri/Cepaf). E-mail: cristiano@epagri.sc.gov.br.

${ }^{4}$ Doutorado em Geografia pela Sorbonne Nouvelle - Institut des Hautes Études de l'Amérique Latine. Pesquisadora do Centre National de la Recherche Scientifique, UMR 5281 ART-Dev, Montpellier, França. Professora visitante no Centro de Desenvolvimento Sustentável da Universidade de Brasília (UnB). E-mail: ludivine.eloy@univ-montp3.fr.
} 
pluriatividade e multifuncionalidade agrícola (SCHNEIDER, 2003; CAZELLA; BONNAL; MALUF, 2009).

Este artigo tem por objetivo principal compreender o caráter multilocalizado de famílias de agricultores com destaque para fluxos de recursos - alimento, financeiro e trabalho - entre os integrantes familiares que permanecem e aqueles que residem fora da unidade agrícola. De forma específica, discutem-se as principais características dos sistemas agrícolas de famílias multi e monolocalizadas entrevistadas no quadro do projeto de pesquisa. A escolha da região Oeste de Santa Catarina para realizar a pesquisa de campo foi feita em virtude da diversidade social e da importância socioeconômica da agricultura familiar ali existente, bem como ao apoio institucional à pesquisa de campo do serviço público estadual de pesquisa e extensão rural. $\mathrm{O}$ primeiro tópico deste artigo discute a noção de multilocalização familiar e detalha a metodologia de pesquisa. $\mathrm{O}$ segundo discute os sistemas produtivos e alimentares de distintas categorias de agricultores de forma a contemplar a diversidade social da agricultura familiar da região de estudo. O terceiro analisa as situações de multilocalização e monolocalização dessas famílias segundo as categorias da tipologia adotada. Nas considerações finais, os principais aspectos que caracterizam a multilocalização familiar na região de estudo são sintetizados.

\section{Definindo a multilocalização familiar e principais procedimentos metodológicos}

A noção de sistemas familiares multilocalizados foi formulada originalmente para analisar as relações entre membros de famílias rurais em países latino-americanos marcados por intensos processos migratórios da população rural (CORTES et al., 2014; FRÉGUIN-GRESH et al., 2015; FRÉGUIN-GRESH; TROUSSELLE; CORTES, 2015; CORTES; TORAL, 2016). A abordagem teórico-metodológica dos sistemas familiares multilocalizados complementa o conceito de "migração", geralmente entendido como o conjunto de deslocamentos nacionais e internacionais de pessoas, que implica mudança de residência de média e longa duração, bem como a ideia de "mobilidade", que consiste no conjunto de todas as formas de deslocamentos, sejam elas pontuais ou recorrentes, associadas à execução de atividades diversas (FRÉGUIN-GRESH et al., 2015).

Os sistemas familiares multilocalizados no meio rural correspondem aos "[...] espaços de dispersão e de circulação de recursos humanos, sociais e econômicos, dentro dos quais evoluem as famílias rurais a fim de garantir, de manter ou de melhorar seus meios de existência" (FRÉGUINGRESH et al., 2015, p. 17, tradução nossa). Esta noção permite, portanto, compreender as relações entre os integrantes de famílias de agricultores que se dispersam no tempo e no espaço sem que ocorram rupturas 
completas com as unidades agrícolas familiares, já que determinados vínculos sociorreprodutivos são mantidos entre quem sai e quem fica, não sendo possível o entendimento da sua reprodução social sem considerá-los (ELOY, 2009; CORTES et al., 2014).

Neste estudo, a distinção entre as condições familiares rurais multi e monolocalizadas teve por base a definição de famílias multilocalizadas, compreendidas como aquelas em que um ou mais membros residem fora da Unidade Agrícola Familiar (UAF), mas participam do processo de reprodução socioeconômica dessa unidade por meio do compartilhamento de recursos monetários, alimentares e trabalho. Essa participação contempla os auxílios aportados pelos integrantes que trabalham e gerem a UAF, sem que necessariamente ocorra a retribuição com trabalho ou com recursos financeiros por parte dos beneficiários externos.

A escolha dos municípios para realização da pesquisa de campo adotou como critério a localização no entorno de Chapecó, municípiopolo da região de estudo. Com seus 220.367 habitantes, esse município registra a quinta maior população e o sexto Produto Interno Bruto dentre os municípios catarinenses (IBGE, 2019). À exceção de Chapecó, os nove outros municípios contemplados pela pesquisa apresentam populações estimadas pelo Instituto Brasileiro de Geografia e Estatística para 2019 que variam de 28.706 (Xaxim) a apenas 1.505 (Paial) habitantes. A maioria desses municípios possui características rurais, com atividades econômicas vinculadas ao setor agropecuário e sedes municipais desprovidas de diversos serviços, notadamente daqueles associados ao ensino superior e atendimentos especializados na área da saúde.

Ao todo, 49 famílias de agricultores foram entrevistadas por meio da aplicação de um questionário semiestruturado. A escolha dessas famílias procurou contemplar a heterogeneidade tanto socioeconômica quanto dos sistemas produtivos da agricultura familiar da região. Para tanto, quatro categorias de agricultores familiares foram consideradas: a) com contratos de integração com agroindústrias; b) que praticam agricultura convencional; c) inseridas em Circuitos Curtos de Comercialização (CCC); d) agricultores pouco inseridos em mercados. ${ }^{5}$ Para as três primeiras categorias de agricultores, o principal critério adotado na construção dessa tipologia foi a forma de inserção aos mercados, a partir de três distintas modalidades: produtores de commodities com contratos formais de integração com as agroindústrias de aves e suínos; produtores de commodities, mas sem esse tipo de contrato (produtores de grãos e de leite); e famílias em CCC.

\footnotetext{
${ }^{5}$ Nesta categoria encontram-se famílias de agricultores pobres beneficiadas por políticas públicas de enfrentamento da pobreza e famílias indígenas.
} 
Embora as duas primeiras categorias sejam constituídas por produtores de matérias-primas para as grandes indústrias agroalimentares, a distinção se deve às diferenças no grau de autonomia em relação aos mercados. Os agricultores integrados às agroindústrias de carnes seguem estritamente o que determina a assistência técnica da empresa, tanto em relação ao manejo dos animais quanto às exigências sanitárias. Já os agricultores que produzem matérias-primas sem contratos de integração têm mais autonomia para definir as atividades que vão desenvolver em suas unidades agrícolas, os respectivos sistemas de produção, o tipo de tecnologia e as empresas para as quais vendem sua produção.

Além dos mercados de commodities, uma parcela de agricultores produz alimentos para CCC. Essa categoria de agricultores, por sua vez, se divide em duas subcategorias, tendo por base a existência ou não na UAF de algum tipo de unidade de transformação de produtos agropecuários. A comercialização ocorre em feiras livres, venda direta aos consumidores ou participação em programas de compra institucional, como o Programa de Aquisição de alimentos (PAA) e o Programa Nacional de Alimentação Escolar (Pnae). ${ }^{6}$ Uma parte desse tipo de comercialização ocorre na informalidade, sem nota fiscal e inspeção sanitária dos produtos processados vendidos. Essa produção artesanal de alimentos constitui um vibrante mercado informal, que na região são denominados de forma genérica por produtos coloniais (DORIGON, 2008; DORIGON; RENK, 2011; DORIGON et al., 2015).

Esse tipo de mercado desempenha um papel decisivo no processo de inovação produtiva e organizacional em curso na região. Os agricultores que já estão estabelecidos nesses mercados informais e desejam migrar para o mercado formal constroem "agroindústrias familiares rurais", contando geralmente com o apoio técnico de Organizações Não Governamentais (ONG), da Empresa de Pesquisa Agropecuária e Extensão Rural (Epagri) e de serviços públicos municipais. Para viabilizar a assistência técnica em logística, marketing, tributária e sanitária, os proprietários dessas pequenas unidades de processamento se organizam em redes de cooperativas, descentralizadas e com controle social dos agricultores, as quais coexistem com as grandes cooperativas voltadas a mercados de commodities e/ ou regionais (DORIGON, 2008).

Note-se que uma mesma família de agricultor pode, no entanto, participar de diferentes mercados. A título de exemplo, é possível produzir aves ou suínos com contrato de integração para uma

\footnotetext{
${ }^{6}$ A reestruturação do Pnae para contemplar a compra de alimentos da agricultura familiar e a criação no PAA se inserem no escopo do Programa Fome Zero instituído a partir de 2003, como principal política de enfrentamento da pobreza (GRISA; ZIMMERMANN, 2015; GRISA; PORTO, 2015; TRICHES, 2015).
} 
agroindústria alimentar e leite para um laticínio ou cooperativa. $\mathrm{Ou}$ vender leite para a indústria e produzir embutidos de carne suína sob encomenda para fregueses fidelizados. Entretanto, não é frequente que uma mesma família participe do mercado de commodities e de circuitos curtos de comercialização, pois a reconversão para os CCC, na maioria dos casos, resulta do processo de exclusão do mercado de matériasprimas.

A categoria de agricultores pouco inseridos nos mercados, que inclui "agricultores pobres" e indígenas, não tem relação direta com o sistema produtivo adotado, mas com a condição socioeconômica e étnica. O valor monetário que define os beneficiários de programas sociais é o critério que delimita o número de famílias ou pessoas pobres e extremamente pobres no Brasil. A linha da pobreza extrema, adotada desde 2015, para elegibilidade em relação ao benefício do Programa Bolsa Família (PBF) e do Programa Brasil Sem Miséria (PBSM), corresponde à renda domiciliar per capita de até $\mathrm{R} \$ 89,00$, enquanto a linha da pobreza contempla famílias que possuem essa renda entre R\$ 89,00 e R\$ 178,00 (MDS, 2015). ${ }^{7}$ Neste estudo integraram essa categoria famílias beneficiadas por esses dois programas.

A inclusão de famílias indígenas, por sua vez, decorre da região Oeste de Santa Catarina abrigar sete das 25 Terras Indígenas (TI) ${ }^{8}$ catarinenses e mais de $65 \%$ da população indígena do estado, que era de 10.369 pessoas em 2012 (BRIGHENTI, 2012). A população originária do Oeste de Santa Catarina era composta principalmente por indígenas das etnias Kaigang e Guarani, que foram expropriadas das terras, sobretudo, pelo processo de colonização da região promovido pelo Estado (D'ANGELIS, 1995; NÖTZOLD, 2003). Muitas famílias que sofreram esse tipo de privação ficaram desprovidas de terras por décadas, trabalhando como agregadas e ocupando terras devolutas, normalmente, nas encostas de rios (BRIGHENTI, 2012). Embora muitas das atuais TI antecedam a Constituição Federal de 1988, que assegurou aos indígenas a posse da terra por comprovações históricas, diversos processos de retomada das terras por esses povos tradicionais tiveram início quando a Constituição foi promulgada (GOULART, 2009; VALENTINI; RADIN, 2011).

A maioria dos estudos empíricos sobre a agricultura familiar da região desconsidera a situação específica dos povos tradicionais. Entre os indígenas foram escolhidas famílias dos municípios de Chapecó e

\footnotetext{
${ }^{7}$ O PBF foi implementado em 2003 e o PBSM em 2011 com a finalidade de assistir famílias pobres já atendidas pelo PBF, por meio da melhoria no acesso à saúde, à educação e ao emprego (FAO, 2014). No meio rural, o PBSM tem uma ação denominada Programa de Fomento às Atividades Produtivas Rurais, que combina a transferência direta de recursos financeiros não reembolsáveis com ações de acompanhamento social e produtivo (MDS, 2017).

8 Toldo Imbú (Abelardo Luz); Kondá e Toldo Chimbangue (Chapecó); Xapecó (Ipuaçu e Entre Rios); Toldo Pinhal (Seara); Fraiburgo (Fraiburgo) e Araçaí (Saudades).
} 
Seara, onde existem TI, além de uma família de Arvoredo, que não reside nessas áreas coletivas. Nem todas as famílias dessa etnia residem nas TI por diversas razões, com destaque para a não adaptação ao sistema de vida comunitária ali adotado, desejo de residir próximas de centros urbanos e, por vezes, a negação de pertencimento a essa etnia.

Definidas essas categorias, procurou-se atender dois outros critérios na escolha das famílias entrevistadas. O primeiro consistiu em assegurar uma distribuição equitativa de famílias entre os municípios pesquisados e, o segundo, em contemplar o caráter multilocalizado de integrantes das famílias rurais. Para a escolha das famílias de agricultores contou-se com o apoio, principalmente, de extensionistas rurais dos escritórios municipais da Epagri, os quais sugeriram as famílias, fizeram os contatos prévios, agendaram as entrevistas e, na maioria dos casos, acompanharam os pesquisadores durante a aplicação dos questionários. Nos municípios de Arvoredo e Paial teve-se também o apoio de técnicos das secretarias municipais de assistência social, já que a maioria das famílias pobres entrevistadas reside nesses municípios.

\section{Tipologia das famílias entrevistadas: principais características dos sistemas produtivos}

O Quadro 1, a seguir, apresenta a distribuição das famílias de agricultores entrevistadas segundo as distintas categorias da tipologia e a condição de localização dos seus membros. Pela definição de famílias multilocalizadas adotada neste estudo, os membros externos considerados na análise mantêm relações de compartilhamento de recursos com aqueles que permanecem na UAF. Na sequência, as principais características dessas categorias são analisadas.

Quadro 1 - Distribuição das famílias de agricultores entrevistados segundo as categorias de diversidade socioeconômica e de localização dos seus membros

\begin{tabular}{c|c|c|c|c|c}
\hline Categoria & Integrado & Convencional & CCC & $\begin{array}{c}\text { Pouco inserido } \\
\text { em mercados }\end{array}$ & Total \\
\hline Monolocalizadas & 3 & 3 & 8 & 11 & 25 \\
\hline Multilocalizadas & 6 & 5 & 11 & 2 & 24 \\
\hline Total & 9 & 8 & 19 & 13 & 49 \\
\hline
\end{tabular}

*CCC: Circuito Curto de Comercialização.

Fonte: Pesquisa de campo. 


\section{a) Famílias de agricultores integradas às agroindústrias de carnes}

Essa categoria contempla as unidades agrícolas familiares que produzem suínos e aves para as indústrias agroalimentares e cuja relação comercial é regulada por contratos de integração vertical. Entende-se por integração vertical o sistema por meio do qual as indústrias fornecem as matrizes ou leitões (suinocultores) e os pintinhos (avicultores), a alimentação e a medicação para os animais, bem como a assistência técnica e a garantia de compra dos animais. O preço dos insumos e o valor pago pela matéria-prima aos agricultores são definidos pelas empresas integradoras. Por sua vez, os agricultores são responsáveis pelos investimentos em instalações, equipamentos e pela mão de obra demandada nas atividades. Essa modalidade de contrato representa a base produtiva da matéria-prima das indústrias agroalimentares situadas em Chapecó e região. Das 49 famílias entrevistadas, nove possuem contratos de integração (produtores de suínos ou aves), sendo três monolocalizadas e seis multilocalizadas.

\section{b) Famílias que praticam agricultura convencional}

A definição de "agricultura convencional" abarca os agricultores que produzem matérias-primas para mercados competitivos, mas que, diferente dos produtores de suínos e aves, não estabelecem contratos de integração com as empresas com as quais comercializam seus produtos agropecuários. Essa categoria de agricultores produz, principalmente, grãos (milho e soja), comercializados com cerealistas e cooperativas da região, e leite, também vendido para as cooperativas, com destaque para a Cooperativa Central Aurora, e diversas outras indústrias, como Tirol, Piracanjuba, Nestlé, Lactalis, dentre outros laticínios de médio porte. Esses agricultores, em geral, possuem mais de uma atividade agropecuária para fins comerciais e representam a categoria com o maior número de agricultores na região. Das oito famílias entrevistadas dessa categoria, três são monolocalizadas e cinco multilocalizadas.

\section{c) Famílias inseridas em Circuitos Curtos de Comercialização}

As UAF desta categoria, em geral, têm menores áreas de terras e capital, e não acompanharam as exigências de investimentos para a modernização das atividades agrícolas ou para a ampliação da escala de produção, sendo excluídas dos mercados de commodities. Trata-se de casos de reconversão para produção de alimentos de qualidade diferenciada produtos agroecológicos, orgânicos, coloniais, crioulos, dentre outros. $\mathrm{Na}$ região Oeste de Santa Catarina, esse tipo de agricultura está associado ao debate da agroecologia fomentado por organizações sindicais, movimentos sociais e ONG que atuam na agricultura familiar. Essa modalidade de agricultura pode ser definida como um conjunto de 
concepções científicas, sociotécnicas e políticas que tem como princípio básico o uso dos recursos naturais, visando à produção de alimentos saudáveis, à redução da dependência de energia externa e do impacto ambiental da atividade agropecuária, com o propósito de valorizar as famílias de agricultores, seu trabalho e sua cultura (WEZEL et al., 2009). Embora minoritários, são agricultores inovadores do ponto de vista técnico e organizacional que, na sua maioria, estão conectados a redes de cooperação, com destaque para a Rede Ecovida de Agroecologia, a qual conta com o apoio de diversas ONG e efetua a denominada certificação participativa de produtos orgânicos. Nessa categoria de agricultores encontram-se também os beneficiários do Pnae e do PAA. Do total de 49 famílias entrevistadas, 19 correspondem a agricultores inseridos em CCC, dos quais oito são monolocalizadas e 11 multilocalizadas.

\section{d) Famílias pouco inseridas nos mercados}

A grande maioria das famílias rurais pobres da região Oeste de Santa Catarina pertence à etnia cabocla, fruto da miscigenação entre índios, luso-brasileiros e ex-escravos negros. A condição de pobreza vivida por essas famílias está correlacionada com a história da ocupação da região, na qual uma parcela significativa foi expropriada de suas terras (RENK, 2006). As famílias caboclas que habitam no meio rural acessaram a terra ou o lote de maneira variada: i) aquisição com recursos próprios; ii) herança; iii) reforma agrária; iv) concessão por familiares ou ex-empregadores; v) arrendamento; vi) ocupação de terras, em antigas vilas de ex-serrarias, em áreas de risco ambiental e no domínio de rodovias; vii) vilas rurais de ervateiras, onde residem prestadores de serviços no corte de erva-mate. As quantidades de terra que a maioria das famílias caboclas pobres dispõe são pequenas (entre 0,5 e $13 \mathrm{ha}$ ) e, em alguns casos, correspondem a lotes que não passam de $100 \mathrm{~m}^{2}$ (TECCHIO, 2017; 2012; CIPRIANO, 2017; MELO, 2015; PODELESKI, 2014). Não obstante, parte das famílias caboclas compartilha a terra, lote e, por vezes, a casa com outras famílias, quase sempre com relações de parentesco. De maneira geral, essas famílias encontram dificuldades de se viabilizar economicamente, pois sofrem privação dos principais meios de produção, bem como de infraestrutura básica e serviços públicos de saúde, educação e transporte.

Em relação às famílias indígenas, o acesso a terra é bastante diversificado, já que nas TI pode ocorrer a divisão informal de lotes, assim como o uso coletivo. Além disso, muitas famílias indígenas da região continuam privadas ou possuem acesso precário a terra, principalmente em função de as TI às quais pertencem ainda estar em processo de demarcação. Uma parcela significativa das famílias sem acesso a terra trabalha como assalariados em frigoríficos, empresas de carregamento de frangos e atividades sazonais na agricultura e, outra, vive na condição de pobreza, 
sendo assistida pelo PBF (TECCHIO, 2017; 2012). A produção de alimentos para o autoconsumo, a confecção de artesanatos para a comercialização, a caça, a pesca e a coleta de alimentos é praticada por muitas das famílias residentes em TI. Das 13 famílias pouco inseridas em mercados entrevistadas, 11 são monolocalizadas e duas são multilocalizadas.

A fim de aprofundar a caracterização das diferentes categorias de agricultores analisadas neste artigo, na sequência, dois fatores considerados estratégicos no processo de definição dos distintos sistemas produtivos e alimentares são discutidos: a estrutura fundiária e a produção para o autoconsumo.

\section{Estrutura fundiária e produção para autoconsumo das famílias entrevistadas}

Em relação à estrutura fundiária das famílias entrevistadas, as áreas médias dos estabelecimentos rurais não apresentam diferenças significativas entre as categorias de agricultura convencional e com contratos de integração, quer seja mono ou multilocalizadas. As famílias da categoria convencional mono e multilocalizadas possuem, respectivamente, área média de 19,5 ha e 16,3 ha. Já as famílias monolocalizadas com contrato de integração possuem área média de 42,3 hectares, enquanto a média de área das famílias multilocalizadas dessa categoria é de 17 ha.

O tamanho médio dos estabelecimentos rurais das famílias que participam de CCC, por sua vez, é menor que nas duas categorias anteriores, com áreas praticamente iguais no que concerne às duas categorias de localização dos integrantes do grupo familiar: as famílias monolocalizadas possuem uma área média de 9,2 ha e as multilocalizadas 8,7 ha. A menor quantidade de terra das famílias inseridas em CCC é uma das razões que as levaram a se orientar para atividades de maior densidade econômica, como olericultura, fruticultura e processamento de produtos agropecuários.

Assim, constata-se não haver diferenças expressivas de área entre as famílias mono e multilocalizadas, o que não é verdade em relação ao tipo de inserção nos diferentes mercados. Entre as famílias produtoras de commodities, com ou sem contratos de integração, as diferenças não estão no tamanho da área do estabelecimento rural, mas na maior quantidade de capital investido nas unidades integradas às agroindústrias, com destaque para as instalações e equipamentos dos sistemas produtivos de aves e suínos.

Já entre as famílias pouco inseridas nos mercados, o acesso a terra é distinto entre as duas subcategorias (pobres e indígenas). A pouca terra é a principal variável que define a condição de pobreza das primeiras. Das nove famílias pobres entrevistadas, oito delas são monolocalizadas e 
possuem uma área média de 2,7 ha. Apenas uma família pobre multilocalizada foi entrevistada, a qual é proprietária de 13 ha. Quanto às famílias indígenas, três vivem em TI e uma reside fora da área indígena num pequeno lote de terra de 0,2 ha. Das que vivem na TI, uma declarou não possuir lote individual. As duas outras dispõem, respectivamente, de 6 ha e 1,5 ha, sendo esta última a única família indígena que se caracteriza como multilocalizada.

De modo geral, o tamanho das UAF não tem correlação com a situação localizacional dos seus membros, salvo entre as famílias pouco inseridas nos mercados. Uma explicação para o predomínio da monolocalização entre essas famílias tem a ver com a escassez de terras e a precária base tecnológica das suas unidades produtivas, o que não permite a produção de alimentos suficientes para serem doados para membros externos.

Em relação à produção para o autoconsumo, diversos estudos recentes apontam a relevância desse tipo de produção de alimentos para a segurança alimentar e nutricional das famílias de agricultores (GAZOLLA; SCHNEIDER, 2005; GRISA, 2007; MENASCHE; MARQUES; ZANETTI, 2008; GRISA; SCHNEIDER; CONTERATO, 2013). Nesta análise, duas variáveis foram consideradas para avaliar a importância do autoconsumo das famílias entrevistadas: a quantidade de terra destinada à produção de alimentos para o consumo familiar e o valor que as famílias estimam economizar graças à produção de alimentos para o autoconsumo. O Quadro 2 sintetiza essas informações e demonstra que as famílias que possuem uma área média maior para o autoconsumo são as inseridas nos CCC. Essa categoria de agricultores apresenta em média aproximadamente 0,5 ha, tanto entre as famílias monolocalizadas quanto entre as multilocalizadas. Trata-se também da categoria que estima economizar os valores monetários mais expressivos graças a esse tipo de produção: $\mathrm{R} \$ 1.350,00$ mensais para as famílias monolocalizadas e $\mathrm{R} \$ \mathbf{8 8 7 , 0 0}$ mensais para as multilocalizadas. Dentre as possíveis explicações para esses maiores valores atribuídos pelas famílias que integram o CCC está a importância dada à produção de alimentos para fins comerciais, sendo que parte deles é destinada para o autoconsumo. Além disso, esses agricultores têm uma percepção mais apurada sobre o valor monetário da produção para o autoconsumo, captada com seus clientes durante as vendas diretas. Essa valorização tende a ser subestimada pelos agricultores das demais categorias, os quais não comercializam diretamente com o consumidor final.

Entre os agricultores convencionais, a área dedicada para o autoconsumo é um pouco menor que aquela dos agricultores da categoria CCC, sendo praticamente a mesma área para as famílias mono e multilocalizadas, com cerca de 0,3 ha. Não há diferenças significativas nos valores estimados de economia com a produção para o autoconsumo entre esses dois tipos de famílias, com aproximadamente $\mathrm{R} \$ 740,00$. 
Quadro 2 - Área média dedicada à produção para autoconsumo, número de famílias e valor médio estimado de economia com a produção para autoconsumo segundo critérios de multilocalização ou monolocalização e categorias da tipologia de análise

\begin{tabular}{c|c|c}
\hline Categoria & Monolocalizada & Multilocalizada \\
\hline \multicolumn{2}{c|}{ Área média (ha) e Economia estimada com autoconsumo (R\$/mês) } \\
\hline CCC & $0,49(8 \mathrm{fam})$. & $0,41(11 \mathrm{fam})$. \\
& $1.350,00$ & 887,00 \\
\hline \multirow{2}{*}{ Convencional } & $0,34(3 \mathrm{fam})$. & 740,00 \\
\hline Integrado & 733,33 & $0,43(6 \mathrm{fam})$. \\
& $0,23(3 \mathrm{fam})$. & 885,00 \\
\hline Pouco inserido nos & 500,00 & $1,25(2 \mathrm{fam})$. \\
mercados & $0,19(11 \mathrm{fam})$. & 600,00 \\
\hline
\end{tabular}

*CCC: Circuito Curto de Comercialização.

Fonte: Pesquisa de campo.

Quanto às famílias integradas, entre as monolocalizadas observa-se tanto uma área menor destinada ao autoconsumo $(0,2 \mathrm{ha})$ quanto valores monetários estimados menores de economia decorrente da produção de alimentos para o consumo familiar ( $\mathrm{R} \$ 500,00$ mensais), quando comparadas às categorias de CCC e de convencionais. Nas famílias integradas multilocalizadas percebe-se o destino de uma área para o autoconsumo um pouco maior $(0,4 \mathrm{ha})$, bem como uma maior economia associada à produção para o autoconsumo ( $\mathrm{R} \$ 885,00$ mensais).

Essa relativa menor produção de alimentos para o autoconsumo das famílias integradas monolocalizadas provavelmente está associada à escassa disponibilidade de mão de obra para esse tipo de produção em comparação às categorias CCC e convencional, pois a mão de obra disponível nas famílias de agricultores integrados é absorvida pelas criações de aves e suínos. Já as diferenças de áreas e valores entre as famílias integradas multilocalizadas e monolocalizadas, uma possível explicação é que, no caso da primeira situação, as famílias contam com a ajuda de integrantes familiares que residem fora e que nos fins de semana e feriados trabalham nas hortas, pomares e no abate de animais (bovinos, suínos e aves). Em contrapartida, esses integrantes levam alimentos para suas residências nas cidades. De modo geral, não é possível afirmar que o sistema de integração compromete de forma acentuada a produção de alimentos para o autoconsumo, embora algumas práticas tradicionais 
relacionadas ao abate de animais e à transformação de carnes em embutidos sejam interditadas pelas empresas integradoras.

No caso das famílias pouco inseridas em mercados, do total de 13 entrevistadas, 11 são monolocalizadas, com área média destinada ao autoconsumo de apenas 0,19 ha e valor economizado com esse tipo de produção de R \$ 661,00 mensais. Há apenas duas famílias dessa categoria multilocalizadas, o que limita a comparação com as demais, cuja área destinada para o autoconsumo está bem acima da média (1,25 ha). A economia estimada é de $\mathrm{R} \$ 600,00$ mensais com o autoconsumo.

\section{Entre campo e cidade: entendendo a multilocalização familiar}

O estudo dos fluxos de alimentos, trabalho e demais recursos entre os integrantes das famílias rurais permite evidenciar a complexa configuração socioespacial dos sistemas produtivos. Antes de analisar este último aspecto, convém diferenciar as noções de multilocalização familiar e de pluriatividade agrícola, dadas as suas interfaces conceituais. $O$ tema da multilocalização familiar não configura necessariamente situações de pluriatividade agrícola, noção que compreende o exercício de trabalho remunerado, em geral, realizado fora da unidade agrícola, mas cujos membros pluriativos, residentes ou não nessas unidades, compartilham de forma sistemática trabalho e/ou recursos financeiros com os demais integrantes da UAF (SCHNEIDER, 2003). Dessa forma, tanto as categorias de agricultores monolocalizadas quanto as multilocalizadas aqui analisadas têm casos de pluriatividade de membros da UAF. Ou seja, alguns integrantes de famílias mono e multilocalizadas exercem outras atividades produtivas remuneradas, mantendo vínculos produtivos com a unidade agrícola.

Nos casos de pluriatividade em famílias monolocalizadas, os membros pluriativos residem na UAF. Já quando quem exerce outra atividade remunerada reside fora da $\mathrm{UAF}$, mas trabalha parte do seu tempo na unidade agrícola, têm-se situações de pluriatividade associada à condição de multilocalização familiar. Nem todas as situações de multilocalização correspondem, no entanto, ao exercício de outra atividade remunerada fora do estabelecimento familiar. A maioria dos filhos de agricultores que habita em outros municípios com o propósito de estudar não exerce trabalho remunerado. Esse já não é o caso, por exemplo, de um jovem agricultor entrevistado, em processo de assumir o estabelecimento familiar em função da idade avançada dos pais, cuja residência se encontra noutro município, onde sua esposa e filhas trabalham e gerenciam um pequeno estabelecimento comercial da família. Mesmo que as rendas das duas atividades sejam independentes, como destaca Schneider (2003), sempre existem "vasos comunicantes" entre as distintas fontes de rendas que configuram as situações de pluriatividade. Outro 
aspecto revelado neste estudo é que as situações de pluriatividade não correspondem exclusivamente a trabalhos externos realizados nas zonas urbanas dos municípios pesquisados. Em alguns casos constatou-se o assalariamento sazonal em atividade agropecuária e a prestação de serviços diversos com máquinas e equipamentos em outras unidades produtivas.

O Quadro 1 evidencia que as 49 famílias de agricultores entrevistadas se dividem praticamente meio a meio em relação aos critérios de multilocalização (24 famílias) e monolocalização (25 famílias) dos integrantes do núcleo familiar. As quatro categorias de agricultores analisadas no tópico anterior apresentam, pelo menos, um caso de incidência de multilocalização e, em todas, o principal elemento definidor dessa condição está associado à transferência de recursos da UAF para integrantes familiares que residem fora da unidade produtiva, com destaque para os produtos alimentares. Não se constatou nenhuma situação de família multilocalizada com transferências significativas de recursos externos para o interior da Unidade Agrícola Familiar. Ou seja, os fluxos de alimentos acontecem principalmente no sentido da zona rural para a zona urbana, servindo de "apoio" para membros da família assalariados ou estudantes, ao contrário da representação do senso comum, que preconiza a transferência de recursos urbanos para os estabelecimentos rurais.

Em alguns casos se observou a coparticipação em despesas relacionadas à aquisição de insumos, cujo principal propósito consiste em produzir alimentos destinados para o autoconsumo tanto dos membros familiares que residem na UAF quanto daqueles que moram fora. Um exemplo recorrente é a engorda de suínos e bovinos com a finalidade de abater e transformar parte da carne, em especial a suína, em embutidos para o consumo familiar. A compra de ração animal compartilhada entre os familiares internos e externos à UAF representa, no entanto, mais uma exceção do que a regra, pois o que predomina é a transferência de alimentos da Unidade Agrícola Familiar para os membros externos sem, necessariamente, ocorrer a contrapartida de recursos financeiros ou mesmo de trabalho.

As constantes visitas dos familiares externos aos membros da UAF, sobretudo nos finais de semana e dias de feriado, além de ser um momento de convivência familiar e comunitária, propiciam a execução de atividades agrícolas esporádicas motivadas pela possibilidade de aportar alimentos para o consumo dos integrantes do seu núcleo familiar urbano. Os abates de animais e sua transformação para o autoconsumo familiar são efetuados, quase sempre, durante essas visitas.

Dentre as 24 famílias multilocalizadas, as ocupações mais recorrentes dos 42 membros familiares que residem fora e compartilham recursos 
alimentares, monetários e trabalho com os integrantes da UAF referemse, por ordem decrescente de importância, a assalariados urbanos, estudantes, atividades por conta própria e assalariados rurais. Integrantes externos de 15 famílias multilocalizadas dedicam parte do seu tempo na UAF, com o predomínio de trabalhos esporádicos. Dos 42 membros externos, mais da metade (24 integrantes) realiza trabalhos na Unidade Agrícola Familiar, sendo seis de forma prioritária e 18 esporadicamente. Esses seis membros externos registrados como "produtor por conta própria" residem fora, mas se deslocam diariamente para trabalhar na UAF. O Quadro 3, a seguir, apresenta as principais atividades dos componentes familiares que residem fora da UAF. O município de Chapecó, onde se localizam as principais agroindústrias e instituições de ensino superior da região, dentre as quais uma federal, uma estadual e duas universidades comunitárias, é o principal local de residência e de trabalho desses membros familiares.

Quadro 3 - Atividade principal dos familiares que residem fora da UAF de famílias multilocalizadas

\begin{tabular}{|c|c|c|}
\hline Atividade & Famílias (noo) & Pessoas (no) \\
\hline \multicolumn{3}{|c|}{ Ocupação principal } \\
\hline Assalariado urbano & 14 & 22 \\
\hline Estudante & 5 & 8 \\
\hline Produtor por conta própria & 5 & 6 \\
\hline Assalariado rural & 2 & 2 \\
\hline Outros & 3 & 4 \\
\hline \multicolumn{3}{|c|}{ Dedicação à atividade agrícola na UAF dos residentes externos } \\
\hline Mais de $80 \%$ de trabalho & 5 & 6 \\
\hline Trabalhos esporádicos & 10 & 18 \\
\hline Total & $24^{*}$ & 42 \\
\hline
\end{tabular}

*Quatro famílias têm membros que residem fora, mas não indicaram as suas atividades. Fonte: Pesquisa de campo.

A principal característica das famílias multilocalizadas identificadas neste estudo consiste, portanto, nas transferências de alimentos da UAF para os membros familiares externos. Essa situação pode ter relação direta com o valor dos rendimentos auferidos com essas atividades externas, além do fato de a maioria dos filhos que estuda fora depender 
exclusivamente da renda da UAF. Conforme evidencia o Quadro 3, a condição de assalariado urbano contempla a maioria das famílias multilocalizadas e das pessoas dessas famílias que residem fora da UAF com, respectivamente, 14 famílias e 22 pessoas. No escopo deste estudo não se levantou informações a respeito do tipo de emprego e respectivas remunerações desses assalariados. Uma questão em aberto para novos estudos é se a modesta remuneração das atividades exercidas por esses membros externos explicaria, em grande parte, a inexistência de transferências de recursos financeiros para os familiares que residem e trabalham na UAF?

Se a resposta a essa questão for afirmativa, os aportes de alimentos produzidos nessas unidades para os residentes externos não se limitariam à manutenção de valores simbólicos e culturais, mas representariam, também, uma importante estratégia de segurança alimentar e nutricional. A direção dos fluxos de alimentos do campo para cidade poderia explicar por que a multilocalização é mais recorrente entre famílias inseridas em mercados competitivos e com rendas maiores. Se, por um lado, "manter" filhos na cidade representa uma forma de ascensão social, por outro, mesmo que esses filhos estejam trabalhando, a vida na cidade se torna cada vez mais cara e o repasse de alimentos da UAF passa a ser imprescindível para assegurar a reprodução social de quem migrou.

O estudo realizado por Nesi et al. (2019) sobre a produção para o autoconsumo com 381 famílias de 112 municípios do Oeste de Santa Catarina indica que $51 \%$ dessas famílias têm integrantes externos que se aprovisionam regularmente de alimentos produzidos na UAF. Ao analisarem os valores monetários dessas transferências de alimentos, segundo a percepção dos respondentes, o valor total médio corresponde a cerca de R\$280,00 por mês. Trata-se, portanto, de aproximadamente 30\% do valor do salário mínimo vigente em 2018, o equivalente a um "vale alimentação" propiciado pela UAF.

As categorias de agricultores nas quais predominam casos de multilocalização, em ordem decrescente de importância, são aquelas integradas às agroindústrias de suínos e aves $(66,7 \%)$, as que praticam o que se denominou neste estudo de agricultura convencional $(62,5 \%)$ e as inseridas em circuitos curtos de comercialização (57,9\%). Nesta última categoria percebeu-se entre seus integrantes jovens o desejo de permanecer ou mesmo retornar para a Unidade Agrícola Familiar. Em duas famílias teve-se o retorno de filhos que moravam fora da UAF motivados pela maior renda e demais vantagens propiciadas por esse tipo de sistema produtivo. Outros estudos realizados no estado de Santa Catarina já haviam apontado esse fenômeno (DORIGON, 2008; DORIGON; RENK, 2013; 2015; DORIGON; RENK; SILVA, 2012; MARCONDES et al., 2012). Tanto 
a permanência quanto a volta de filhos reforçam os casos de monolocalização familiar no interior dessa categoria de agricultores.

Entre as famílias indígenas e agricultores pobres constatou-se, ao contrário das demais, o predomínio de famílias monolocalizadas. Em relação à primeira subcategoria, a pesquisa de campo contemplou somente quatro famílias, o que limita o aprofundamento da análise. Dessas, uma não reside em TI e vive em uma pequena área de 0,2 ha adquirida com recursos próprios. As três outras moram e cultivam áreas em regime familiar no interior das TI, sendo uma delas multilocalizada. Trata-se de uma família extensa que possui filhos residentes em áreas urbanas de municípios da região e que se abastecem de alimentos produzidos e coletados por familiares que convivem na TI. Nas quatro famílias indígenas, a produção para autoconsumo é predominante, complementada com coletas de frutos nativos, caça e pesca, práticas tradicionais entre os integrantes dessa etnia.

No caso das nove famílias de agricultores pobres entrevistadas, somente uma é multilocalizada. Diferente da maioria das famílias indígenas que dispõe de terras graças à existência de TI, todas as unidades agrícolas de agricultores pobres se caracterizam pelo acesso precário a terra decorrente de diversos fatores, por vezes, conjugados: pequenas áreas cedidas e compartilhadas por e com terceiros, na maioria dos casos entre parentes, inexistência de título de propriedade da terra, falta de máquinas e equipamentos agrícolas com tração mecânica e desconhecimento ou pouca tradição em cultivar ou criar animais de forma intensiva em pequenas áreas. Essa situação se explica pelo processo de ocupação da região Oeste de Santa Catarina, que se deu com a exclusão, quase sempre violenta, de ancestrais dessas famílias, os quais habitavam a região na condição de posseiros de terras devolutas (MONTEIRO, 1974; AURAS, 1984; RENK, 2006).

O compartilhamento de terras entre famílias rurais pobres foi analisado por Vianna (1989) em estudo sobre os primeiros assentamentos de agricultores sem-terra no Sul do país. Trata-se de um mecanismo de reciprocidade camponesa extremamente importante para sua reprodução social. Por meio do "encosto", como é chamado esse tipo de relação entre parentes, amigos e compadres, um cede uma área para o outro residir e, muitas vezes, cultivar. "O 'encosto' é um momento da cadeia de reciprocidades e significa uma resposta imediata à possibilidade de obtenção do bem 'terra' a prazo, principalmente quando se funda uma nova família" (VIANNA, 1989, p. 19).

A precariedade social dessas famílias não permite o aporte de recursos alimentares e financeiros para membros externos. Somente três dessas famílias mencionaram ter filhos que residem fora, mas em dois casos esses membros externos não mantêm vínculos com a UAF, seja para se 
aprovisionar com alimentos, seja para fornecer algum tipo de auxílio financeiro para os pais agricultores. A maioria reside em áreas de terras cedidas por familiares aposentados, os quais são posseiros das terras que compartilham com filhos, que não lograram sucesso para obter terras próprias para cultivar ou para trabalhar em outras atividades. Em dois casos, os filhos relataram ter residido em zonas urbanas de municípios da região, mas optaram por retornar para o meio rural, apesar da precariedade dos estabelecimentos agrícolas familiares. Além da terra, os parentes aposentados cumprem também o papel de fornecer, com frequência, refeições e alimentos preparados ou não para essas famílias. Em geral são unidades produtivas nas quais a produção para fins comerciais é deficitária ou até mesmo inexistente. Quando ocorrem relações mercantis, o volume de produção comercializado é pequeno, não acessam as principais políticas públicas de apoio à agricultura familiar e muitas dependem de auxílios assistenciais, notadamente do Programa Bolsa Família (PBF). Essa situação de precariedade social, com marcada escassez de terras para cultivar, impede ou dificulta a multilocalização familiar, pois a impossibilidade de produzir e compartilhar gêneros alimentícios ou recursos financeiros com quem reside fora é muito acentuada. Ao contrário, são os escassos recursos existentes na UAF (terra e benefícios previdenciários) que explicam o predomínio de situações de monolocalização.

O tema das aposentadorias rurais merece uma atenção especial nesta análise, dada a marcada incidência de benefícios previdenciários entre as famílias entrevistadas. Trata-se de investigar se existe alguma correlação entre os casos de famílias com membros aposentados e a maior ou menor incidência de um dos tipos de famílias segundo o critério de localização dos seus integrantes?

\section{Previdência social: possíveis correlações com a localização familiar}

A presença ou não de membros aposentados nas famílias entrevistadas não foi critério de seleção das famílias para compor a pesquisa de campo, diferente do que ocorreu, por exemplo, em relação às famílias beneficiadas por políticas públicas de compras institucionais de alimentos da agricultura familiar. Ao todo, 28 famílias, o que equivale a $57 \%$ das 49 famílias entrevistadas, têm membros aposentados ou que recebem o Benefício de Prestação Continuada residindo e, por vezes, trabalhando nas unidades agrícolas. Não raro, esses agricultores idosos são os gestores e principal fonte de trabalho da UAF. Essa é a situação de sete casos, pouco mais de um quarto das famílias com membros aposentados, que apresentam fortes indícios de que a Unidade Agrícola Familiar não terá sucessor para dar continuidade às atividades agropecuárias. Em geral 
possuem filhos que residem fora, que não têm interesse ou condições sociofamiliares para assumir o empreendimento agrícola familiar.

Quatro outras famílias (três pobres e uma indígena) compartilham áreas de terras com parentes aposentados (pais/sogros) e se beneficiam de alimentos e refeições nas residências dos mesmos. Esse compartilhamento de terras não necessariamente implica gestão e trabalho conjunto de um único estabelecimento agropecuário, como acontece na maioria dos demais entrevistados. $\mathrm{O}$ ato de ceder terra, ou de residir próximo de familiares pode ocorrer de forma independente das atividades produtivas empreendidas pela família envolvida no processo de cedência de terra ou de um local de residência. Outro aspecto a ser considerado concerne aos casos que recebem Bolsa Família e residem na mesma unidade com parentes aposentados. Nessas situações, a omissão de informações de compartilhamentos de recursos, sobretudo dos benefícios previdenciários, pode estar associada ao receio de ser excluído do PBF em decorrência da renda familiar ser superior à linha da pobreza estabelecida pelo Programa.

O cruzamento dos dados das famílias aposentadas com as situações de multi e monolocalização familiar revelou, no entanto, não existir uma influência dessa política pública a favor de uma ou outra situação. Das 28 famílias com algum membro aposentado, a metade corresponde a cada uma das duas situações de localização dos membros familiares. O que se percebe é uma forte correlação entre as situações de aposentadorias com as categorias de agricultores pouco inseridos nos mercados e com as que comercializam em circuitos curtos com, respectivamente, $61,5 \%$ e $68,4 \%$ dos casos. Outra categoria de agricultores com presença expressiva de membro aposentado é a dos agricultores convencionais, com metade das oito famílias entrevistadas. Por sua vez, os agricultores integrados registraram um terço com algum membro aposentado.

Entre os agricultores que comercializam em circuitos curtos, conforme já analisado, a produção diversificada de produtos alimentares e a sua importância para o autoconsumo podem estar associadas à presença de membros aposentados. Aqui, as "forças marginais" ou "forças não transferíveis" representadas pelo trabalho de familiares idosos, crianças e mulheres, discutidas no estudo clássico de Tepicht (1973) sobre o campesinato europeu, demonstram toda sua pujança. Diferente da interpretação de Abramovay (1992), que as considera irrelevantes para explicar a persistência na atualidade de uma agricultura familiar moderna inserida nos mercados competitivos, o que este estudo sugere é que essas "forças marginais" contribuem para a persistência de determinadas UAF, com destaque para os casos de pobreza e inserção em CCC. O Quadro 4 sintetiza as correlações entre as famílias aposentadas, as distintas 
categorias de agricultores e as duas situações de localização dos integrantes das unidades familiares entrevistadas.

Quadro 4 - Número de famílias beneficiadas pela Previdência Social por categoria tipológica e situação de localização dos membros familiares

\begin{tabular}{c|c|c|c|c|c}
\hline \multirow{2}{*}{ Categoria } & \multirow{2}{*}{ Monolocalizada } & \multirow{2}{*}{ Multilocalizada } & \multicolumn{2}{|c|}{ Total } & \multirow{2}{*}{$\begin{array}{c}\text { Difícil } \\
\text { sucessão }\end{array}$} \\
\cline { 4 - 5 } & & & $\mathbf{n} \mathbf{( * )}$ & $\%$ & \\
\hline $\begin{array}{c}\text { Pouco inserido } \\
\text { nos mercados }\end{array}$ & 7 & 1 & $8(13)$ & 61,5 & - \\
\hline Integrado & - & 3 & $3(9)$ & 33,3 & 1 \\
\hline Convencional & 2 & 2 & $4(8)$ & 50 & 2 \\
\hline CCC & 5 & 8 & $13(19)$ & 68,4 & 4 \\
\hline Total & $\mathbf{1 4}$ & $\mathbf{1 4}$ & $\mathbf{2 8 ( 4 9 )}$ & $\mathbf{5 7}$ & $\mathbf{7}$ \\
\hline
\end{tabular}

*Total de famílias estudadas.

**CCC: Circuito Curto de Comercialização.

Fonte: Pesquisa de campo.

O estudo de Delgado (2015) revelou a existência, em junho de 2013, de cerca de nove milhões de benefícios previdenciários alocados à categoria de agricultores familiares e 5,3 milhões de famílias que recebiam esse tipo de benefício. Trata-se, portanto, de uma das principais políticas de desenvolvimento rural existentes no país, tanto pelo número de famílias beneficiadas quanto pelo volume de recursos financeiros disponibilizados, que soma cerca de $\mathrm{R} \$ 84$ bilhões ao ano, bem acima do montante aportado pelas demais políticas públicas de apoio à agricultura familiar (CAZELLA, 2017).

\section{Considerações finais}

Este estudo revelou a incidência praticamente igualitária das duas categorias de famílias de agricultores ( 25 mono e 24 multilocalizadas). A principal característica da situação de multilocalização na região de estudo consiste na transferência de recursos, sobretudo alimentar, da Unidade Agrícola Familiar para os integrantes que residem fora e principalmente nas cidades. Ao contrário do que se poderia imaginar, em todas as situações de multilocalização não se verificou nenhum caso de auxílios financeiros aportados por familiares que residem e trabalham fora da Unidade Agrícola Familiar. De forma geral, pode-se afirmar que as famílias de agricultores inseridas em mercados competitivos (integrados, convencionais e CCC) são mais multilocalizadas que aquelas cujos sistemas produtivos e/ou unidades agrícolas são precários do ponto 
de vista socioeconômico (pobres e indígenas). Outra característica reside no fato de uma parcela significativa dos residentes externos realizar trabalhos na Unidade Agrícola Familiar, sendo a maior parte de natureza esporádica. Dos 42 membros externos que mantêm vínculos com as UAF, 18 não auxiliam nas atividades agrícolas, mas 24 executam algum tipo de trabalho nessas unidades, dos quais seis como atividade principal residem fora, mas vão diariamente trabalhar na Unidade Agrícola Familiar - e 18 com trabalhos esporádicos.

A marcada presença de integrantes familiares beneficiados com recursos previdenciários - 57\% das famílias entrevistadas - influencia de forma diferenciada o caráter localizacional dos membros familiares, em especial entre as categorias de agricultores pouco inseridos nos mercados (mais monolocalizadas) e em circuitos curtos de comercialização (mais multilocalizadas). Na primeira, o fato de membros aposentados disporem de pequenas áreas de terras propicia o acolhimento de filhos sem-terra e sem uma profissão não agrícola qualificada. Na segunda, os membros aposentados, além de ceder suas terras para herdeiros, participam ativamente da produção e contribuem, sobretudo, nas atividades de transformação de produtos agroalimentares diferenciados. A existência de agroindústrias familiares está associada, também, a casos de retorno para a UAF de filhos que haviam saído para residir e trabalhar fora.

Quanto à importância da produção de alimentos para o autoconsumo, as famílias que participam dos CCC são as que destinam área média maior para esse fim, com aproximadamente 0,5 ha, tanto entre as famílias monolocalizadas quanto entre as multilocalizadas. Essa é também a categoria que declarou economizar mais em função da produção para o autoconsumo. Os valores mais expressivos podem ser explicados pela maior disponibilidade e variedade de alimentos em suas unidades produtivas e por uma melhor percepção do valor monetário da produção para o autoconsumo, captada com os seus clientes durante as vendas diretas. Embora haja variações entre as categorias, a produção para autoconsumo é relevante em todas, sejam elas mono ou multilocalizadas.

A agricultura de base familiar da região, além de produzir matériasprimas para as indústrias agroalimentares e alimentos para circuitos curtos de comercialização e para autoconsumo, contribui também com a segurança alimentar e nutricional de parte de seus membros que residem fora por meio da doação de alimentos. Apesar deste estudo não ter entrevistado os familiares externos, diversos relatos e informações coletadas apontam nessa direção. As transferências de alimentos incorporam, certamente, outras dimensões menos tangíveis, como as relações afetivas envolvidas no ato de dar e receber alimentos, e a manutenção ou renovação do sentimento de pertencimento a uma determinada cultura, expressa pelos hábitos alimentares. 
Os resultados deste estudo devem ser tomados com prudência em relação aos indígenas, uma vez que somente quatro famílias dessa etnia foram entrevistadas. Já entre as famílias de agricultores pobres, o predomínio da monolocalização não significa a inexistência de migração de membros familiares, mas que esse processo se deu associado ao rompimento de compartilhamentos de recursos intrafamiliares. Nesses casos, a precarização concerne tanto a quem permaneceu na UAF quanto a quem saiu, pois dada a baixa formação e qualificação profissional, estes últimos exercem trabalhos de baixa remuneração. Dois casos de agricultores familiares pobres reforçam essa assertiva, pois se referem a filhos que retornaram para o meio rural, após residirem em zonas urbanas de municípios da região. A principal característica dessa categoria de agricultores é o acesso precário a terra, marcado por relações de reciprocidade com parentes que detêm a posse de pequenas áreas no meio rural e são beneficiários da Previdência Social.

Duas especificidades da região de estudo limitam a generalização dos principais resultados deste estudo para outras realidades socioespaciais. A primeira se refere às suas particularidades socioeconômicas marcadas pela presença de agroindústrias empresariais inseridas nos mercados nacional e internacional, que mantêm vínculos com segmentos da agricultura familiar. A segunda está associada à existência de um município-polo localizado no interior do estado, com mais de $200 \mathrm{mil}$ habitantes, que exerce uma força de atração de jovens rurais de municípios do entorno seja para trabalhar em outros ramos de atividades seja para estudar. Por fim, o enfoque da multilocalização familiar representa um modelo da análise original para pensar as especificidades da agricultura familiar brasileira ao apontar a manutenção de fortes laços, para uma parcela significativa da agricultura familiar, entre quem sai e quem fica na UAF, nem sempre percebido quando se mobiliza a noção de êxodo rural. O estudo dos fluxos de alimentos, trabalho e demais recursos entre os integrantes das famílias rurais permite evidenciar a complexa configuração socioespacial e a diferenciação desses sistemas produtivos.

Novos estudos precisam ser feitos, em especial, a respeito da situação multilocalizacional da família rural representar uma condição social diferenciada ou um recurso particular de algumas famílias de agricultores correlacionado ao processo de transformação da estrutura familiar. Essa condição ou recurso pode ter repercussões ainda pouco conhecidas em distintas dimensões sociais do grupo familiar, a exemplo da qualidade da segurança alimentar e nutricional e da sucessão da Unidade Agrícola Familiar. 


\section{Referências bibliográficas}

ABRAMOVAY, R. Paradigmas do capitalismo agrário em questão. São Paulo: Hucitec/Anpocs/EdUnicamp, 1992.

AURAS, M. Guerra do Contestado: a organização da irmandade cabocla. São Paulo: Cortez, 1984.

BRIGHENTI, C. A. Terras Indígenas em Santa Catarina. In: NOTZOLD, A. L. V.; ROSA, H. A.; BRINGMANN, S. F. (Orgs.). Etnohistória, História Indígena e Educação: contribuições ao debate. Porto Alegre: Palotti, 2012. p. 255-278.

CAZELLA, A. A. Governança fundiária: caracterizar melhor para melhor apoiar. In: MALUF, R. S.; FLEXOR, G. (Orgs.). Questões agrárias, agrícolas e rurais: conjunturas e políticas públicas. Rio de Janeiro: E-papers, 2017. p. 72-81.

CAZELlA, A. A.; BONNAL, P.; MALUF, R. S. (Orgs.). Agricultura familiar: multifuncionalidade e desenvolvimento territorial no Brasil. Rio de Janeiro: Mauad X, 2009.

CIPRIANO, L. O. S. Comunidades Rurais Caboclas no Território Meio Oeste Contestado - SC. 2017. 136 f. Dissertação (Mestrado em Agroecossistemas) - Universidade Federal de Santa Catarina, Florianópolis, 2017. Disponível em: https://repositorio.ufsc.br/handle/ 123456789/185465. Acesso em: 15 jul. 2019.

CORTES, G.; FRÉGUIN-GRESH, S.; GUÉTAT-BERNARD, H.; SOURISSEAU, J. M. LeS systèmes familiaux multi-localisés: un modèle d'analyse original des ruralités aux Suds. Document de travail ART-Dev, 2014, 13 p. Disponível em: https://agritrop.cirad.fr/574121/1/document_574121.pdf. Acesso em: 18 mar. 2018.

CORTES, G.; TORAL, A. V. Coexistences rurales et mobilités spatiales en Bolivie. Les Cahiers d'Outre-Mer, n. 273, p. 43-79, 2016. Disponível em: http://journals.openedition.org/com/7696. Acesso em: 10 jun. 2019.

D'ANGELIS, W. R. Para uma história dos índios do Oeste catarinense. Cadernos do CEOM, Chapecó, n. 1, p. 141-220, 1995.

DELGADO, G. C. Previdência social e desenvolvimento rural. In: GRISA, C.; SCHNEIDER, S. (Orgs.). Políticas públicas de desenvolvimento rural no Brasil. Porto Alegre: UFRGS, 2015. p. 429-442.

DORIGON, C.; RENK, A.; SILVESTRO, M. L.; SILVA, C. A., SAVIO, J. Produtos coloniais: tradição e mudança. Chapecó: Argos, 2015. 432 p.

DORIGON, C. Mercados de produtos coloniais da Região Oeste de Santa Catarina: em construção. 2008. 437 f. Tese (Doutorado em Engenharia de Produção) - Programa de Engenharia de Produção, Coordenação dos Programas de Pós-Graduação de Engenharia - COPPE, Universidade Federal do Rio de Janeiro, Rio de Janeiro, 2008. 
DORIGON, C.; RENK, A. Juventude e as transformações no mundo rural: um estudo de caso do Oeste catarinense. In: Congresso Brasileiro de Sociologia, 17., 2015, Porto Alegre. Anais... Porto Alegre: SBS, 2015. p. 120.

DORIGON, C.; RENK, A. Juventude rural, produtos coloniais e pluriatividade. Chapecó: Argos, 2013. 95 p.

DORIGON, C.; RENK, A. Técnicas e métodos tradicionais de processamento de produtos coloniais: de miudezas de colonos pobres aos mercados de qualidade diferenciada. Agricultura em São Paulo, v. 58, p. 101-113, 2011.

DORIGON, C.; RENK, A.; SILVA, C. A. Produtos coloniais como narrativas de comida e migração no Oeste catarinense. In: Reunião Brasileira de Antropologia, 28., Desafios Antropológicos Contemporâneos, 2012, São Paulo. Anais... Brasília: ABA, 2012. p. 1-20.

ELOY, L. Diversidade alimentar e urbanização: o papel das migrações circulares indígenas no Noroeste Amazônico. Anthropology of food, s. 6, 2009. Disponível em: http://aof.revues.org/index6444.html. Acesso em: 20 nov. 2019.

ELOY, L.; BRONDIZIO, E. S.; DO PATEO, R. New perspectives on mobility, urbanisation and resource management in riverine Amazônia. Bulletin of Latin American Research, n. 34, p. 3-18, 2015.

FRÉGUIN-GRESH, S; TROUSSELLE, A.; CORTES, G. L'agriculture familiale diversifiée multilocalisée au Nicaragua. In: BOSC, P. M. (Coord.). Diversité des agricultures familiales: exister, se transformer, devenir. Éditions Quae, p. 95-110, 2015.

FRÉGUIN-GRESH, S.; CORTES, G.; TROUSSELLE, A.; SOURISSEAU, J. M.; GUETATBERNARD, $\mathrm{H}$. Le système familial multilocalisé: proposition analytique et méthodologique pour interroger les liens entre migrations et développement rural au Sud. Mondes en Développement, v. 43, n. 172, p. 13-32, 2015. Disponível em: https://www.cairn.info/revue-mondes-endeveloppement-2015-4-p-13.htm. Acesso em: 4 mar. 2018.

GAZOLLA, M.; SCHNEIDER, S. As duas "caras" do Pronaf: produtivismo ou fortalecimento da agricultura familiar? In: Congresso Brasileiro de Economia e Sociologia Rural, 43., 2005, Ribeirão Preto, São Paulo. Anais eletrônicos... Ribeirão Preto: Sober, 2005. 21 p.

GOUlART, S. S. Terras indígenas no Oeste Catarinense. Revista Santa Catarina em História, Florianópolis, v. 1, n. 2, p. 39-46, 2009. Disponível em: http://seer.cfh.ufsc.br/index.php/sceh/article/viewFile/137/155. Acesso em: 12 jul. 2019.

GRISA, C. A produção "pro gasto": um estudo comparativo do autoconsumo no Rio Grande do Sul. 2007. 200 f. Dissertação (Mestrado em Desenvolvimento Rural) - Programa de Pós-Graduação em 
Desenvolvimento Rural, Universidade Federal do Rio Grande do Sul, Porto Alegre, 2007. Disponível em: https://lume.ufrgs.br/handle/ 10183/11001. Acesso em: 12 jul. 2019.

GRISA, C.; SCHNEIDER, S.; CONTERATO, M. A. A produção para autoconsumo no Brasil: uma análise a partir do Censo Agropecuário 2006. In: SCHNEIDER, S.; FERREIRA, B.; ALVES, F. (Orgs.). Aspectos multidimensionais da agricultura brasileira: diferentes visões do censo agropecuário 2006. Brasília: IPEA, 2013.

GRISA, C.; PORTO, S. I. Dez anos de PAA: As contribuições e os desafios para o desenvolvimento rural. In: GRISA, C.; SCHNEIDER, S. (Orgs.). Políticas públicas de desenvolvimento rural no Brasil. Porto Alegre: Editora da UFRGS, 2015. p. 155-180.

GRISA, C.; ZIMMERMANN, S. A. Estado e sociedade civil na promoção da segurança alimentar e nutricional no Brasil: a construção do Programa de Aquisição de Alimentos da Agricultura Familiar (PAA). Agroalimentaria, Mérida, Venezuela, v. 21, n. 41, p. 17-36, 2015. Disponível em: https://www.redalyc.org/articulo.oa?id=199243361002. Acesso em: 18 jan. 2019.

INSTITUTO BRASILEIRO DE GEOGRAFIA E ESTATÍSTICA - IBGE. Cidades 2019. Brasil, Santa Catarina, Chapecó. Disponível em: https://cidades.ibge. gov.br/brasil/sc/chapeco/panorama. Acesso em: 25 nov. 2019.

MARCONDES, T.; MIOR, L. C.; REITER, J. M. W.; MONDARDO, M. Os empreendimentos de agregação de valor e as redes de cooperação da agricultura familiar de Santa Catarina. Florianópolis: Epagri, 2012. 34 p. Disponível em: http://docweb.epagri.sc.gov.br/website_cepa/publicacoes/Agre gacao_valor.pdf. Acesso em: 1 nov. 2014.

MELO, D. N. Regularização fundiária em zonas rurais: estudo de caso no Território Meio Oeste Contestado em Santa Catarina. 2015. 204 f. Dissertação (Mestrado em Agroecossistemas) - Universidade Federal de Santa Catarina, Florianópolis, 2015. Disponível em: https://repositorio. ufsc.br/xmlui/handle/123456789/158795. Acesso em: 15 jul. 2019.

MENASCHE, R.; MARQUES, F. C.; ZANETTI, C. Autoconsumo e segurança alimentar: a agricultura familiar a partir dos saberes e práticas da alimentação. Revista de Nutrição, Campinas, v. 21, suplemento, p. 145158, 2008.

MINISTÉRIO DO DESENVOLVIMENTO SOCIAL - MDS. Como funciona. 2015. Disponível em: http://mds.gov.br/assuntos/bolsa-familia/o-quee/como-funciona. Acesso em: 4 mar. 2019.

MINISTÉRIO DO DESENVOLVIMENTO SOCIAL - MDS. Programa Fomento. 2017. Disponível em: http://mds.gov.br/assuntos/seguranca-alimentar/pro grama-fomento. Acesso em: 5 out. 2018. 
MONTEIRO, D. T. Os errantes do novo século. São Paulo: Duas Cidades, 1974.

NASUTI, S. ; ELOY, L. ; RAIMBERT, C. ; LE TORNEAU, F. M. Can rural-urban household mobility indicate differences in resource management within amazonian communities? Bulletin of Latin American Research, n. 34, p. 3552, 2015. Disponível em: https://onlinelibrary.wiley.com/doi/full/ 10.1111/blar.12147. Acesso em: 10 fev. 2019.

NESI, C. N.; DORIGON, C.; BADALOTTI, R. M.; PIEREZAN, S. A transferência de alimentos de agricultores familiares para filhos que moram na cidade: um estudo de caso do Oeste de Santa Catarina. In: Seminário Nacional de Planejamento e Desenvolvimento, 4., 2019, Chapecó. Anais eletrônicos... Chapecó: Argos, 2019. 14 p.

NÖTZOLD, A. L. V. Nosso vizinho Kaingáng. Florianópolis: Imprensa Universitária da UFSC, 2003. 99 p.

ORGANIZAÇÃO DAS NAÇÕES UNIDAS PARA A ALIMENTAÇÃO E A AGRICULTURA - FAO. L'État de l'insécurité alimentaire dans le monde. 2014. Disponível em: http://www.fao.org/3/a-i4030f.pdf. Acesso em: 24 mar. 2018.

PODELESKI, O. S. Estratégias de reprodução social de populações remanescentes do Contestado: o caso da comunidade de Taquaruçu, no Meio-Oeste de Santa Catarina. 2014. 157 f. Dissertação (Mestrado em Agroecossistemas) Universidade Federal de Santa Catarina, Florianópolis, 2014. Disponível em: https://repositorio.ufsc.br/handle/123456789/128956. Acesso em: 15 jul. 2019.

RENK, A. A luta da erva: um ofício étnico da nação brasileira no Oeste catarinense. 2. ed. Chapecó: Argos, 2006. 250 p.

SCHNEIDER, S. A pluriatividade na agricultura familiar. Porto Alegre: UFRGS, 2003.

TECCHIO, A. Políticas públicas de desenvolvimento territorial e superação da pobreza no meio rural brasileiro: estudo de caso no Território Meio Oeste Contestado (SC). 2012. 183 f. Dissertação (Mestrado em Agroecossistemas) - Universidade Federal de Santa Catarina, Florianópolis, 2012. Disponível em: https://repositorio.ufsc.br/xmlui/ handle/123456789/99407. Acesso em: 10 jun. 2019.

TECCHIO, A. Pobreza e territorialização da ação pública no Território Meio Oeste Contestado (SC). 2017. 289 f. Tese (Doutorado em Ciências Sociais) Universidade Federal Rural do Rio de Janeiro, Rio de Janeiro, 2017. Disponível em: https://sucupira.capes.gov.br/sucupira/public/ consultas/coleta/trabalhoConclusao/viewTrabalhoConclusao.jsf?popu $\mathrm{p}=$ true\&id_trabalho=5288166. Acesso em: 10. jun. 2019.

TEPICHT, J. Marxisme et agriculture: le paysan polonais. Paris: A. Colin, 1973. $251 \mathrm{p}$. 
TRICHES, R. M. Repensando o mercado da alimentação escolar: novas institucionalidades para o desenvolvimento rural. In: GRISA, C.; SCHNEIDER, S. (Orgs.). Políticas públicas de desenvolvimento rural no Brasil. Porto Alegre: UFRGS, 2015. p. 181-235.

VALENTINI, D. J.; RADIN, J. C. Camponeses no sertão catarinense: a colonização da região Contestado nas primeiras décadas de século XX. In: Simpósio Nacional de História - ANPUH, 26., 2011, São Paulo. Anais eletrônicos... São Paulo, 2011. 14 p. Disponível em: http://www.snh2011. anpuh.org/resources/anais/14/1308581578_ARQUIVO_ANPUHValentini RadinDOC3.pdf. Acesso em: 28 jun. 2014.

VIANNA, A. Organização social e ação política do campesinato: o caso da 'invasão' da Fazenda Annoni. Comunicação no 15, Museu Nacional, UFRJ, 1989.

WEZEL, A.; BELLON, S; DOR'E, T.; FRANCIS, C.; VALLOD, D.; DAVID, C. Agroecology as a science, a movement and a practice. A review. Agronomy for Sustainable Development, v. 29, p. 503-515, 2009. Disponível em: https://link.springer.com/article/10.1051/agro/2009004. Acesso em: 20 nov. 2019.

CAZELlA, Ademir Antonio; DORIGON, Clóvis; NESI, Cristiano Nunes; ELOY, Ludivine. Sistemas agrícolas e alimentares de famílias rurais: análise da multilocalização familiar na região Oeste de Santa Catarina. Estudos Sociedade e Agricultura, v. 28, n. 1, p. 21-47, fev. 2020.

Resumo: (Sistemas agrícolas e alimentares de famílias rurais: análise da multilocalização familiar na região Oeste de Santa Catarina). A migração de agricultores familiares para zonas urbanas costuma ser analisada em termos de êxodo rural. Este artigo mobiliza a noção de multilocalização familiar para discutir distintos fluxos de recursos (alimento, financeiro e trabalho) entre integrantes de Unidades Agrícolas Familiares que permanecem e os que residem fora dessas unidades. Para tanto, realizouse uma pesquisa com 49 famílias de agricultores da região Oeste de Santa Catarina, escolhidas de forma a contemplar a diversidade socioeconômica da agricultura familiar regional. Dentre os principais resultados, constatou-se que a metade dessas famílias é multilocalizada, e que as unidades agrícolas inseridas em mercados competitivos são mais multilocalizadas do que aquelas pouco integradas a esses mercados e com rendas menores. O principal recurso intercambiado é a alimentação da 
unidade agrícola para os integrantes externos, reforçando a importância da produção para autoconsumo tanto para quem permaneceu quanto para quem migrou, mas que reside próximo e mantém vínculos com a família agrícola.

Palavras-chave: agroindústria; autoconsumo; pobreza rural.

Abstract: (Agricultural and food systems of rural families: analysis of familiar multilocalization in western Santa Catarina). The migration of family farmers to urban zones is usually analyzed in terms of rural exodus. This article uses the notion of multilocational families to discuss various flows of resources (food, finance and labor) among farm family members who remain on or live off-farm. Forty-nine farm families in western Santa Catarina were studied, chosen to contemplate the socioeconomic diversity of regional family farming. Among the main results it was found that half of these families are multi-locational and that farms inserted in competitive markets are more multi-located than those with less integration to these markets and lower income. The main resource exchanged is food from the farm sent to those who reside offsite, reinforcing the importance of production for self-consumption both for those who remain and for those who migrate, but who live close to and maintain ties with the family farm.

Keywords: agroindustry; self-consumption; rural poverty.

Creative Commons License. This is an Open Acess article, distributed under the terms of the Creative Commons Attribution License CC BY 4.0 which permits unrestricted use, distribution, and reproduction in any medium. You must give appropriate credit, provide a link to the license, and indicate if changes were made. 